\title{
Outcomes of surgical management of dysplastic oral mucosal lesions versus observation: A systematic analysis
}

\author{
Pelin Güneri ${ }^{*}$, Ellie Maghami ${ }^{2}$, Hayal Boyacioğlu ${ }^{3}$, Allen S Ho ${ }^{4,5}$ and Joel B Epstein ${ }^{2,5}$ \\ 1Department of Oral and Maxillofacial Radiology, School of Dentistry, Ege University, Bornova 35100, Izmir, Turkey \\ 2Division of Otolaryngology-Head and Neck Surgery, City of Hope, 1500 East Duarte Road, Duarte, CA, USA \\ 3Ege University Faculty of Science, Department of Statistics, Bornova 35100, Izmir, Turkey \\ 4Department of Surgery, Cedars-Sinai Medical Center, 8700 Beverly Blvd, Los Angeles CA, USA \\ 5Samuel Oschin Comprehensive Cancer Institute, Cedars-Sinai Medical Center, 8700 Beverly Blvd, Los Angeles CA, USA
}

\begin{abstract}
Background: The aim was to investigate the outcomes of surgical management versus observation of dysplastic oral mucosal lesions.

Method: Twenty-one papers met the a priori inclusion criteria, resulting in a total of 1943 lesions in 1599 patients. Epithelial dysplasia was grouped as "low-grade" and "high-grade". Clinical outcome was established as the proportion of lesions with complete response, partial response, no response, malignant transformation, and recurrence/new lesions. Data on surgical intervention versus no treatment/observation was statistically analyzed.

Results: Surgical management was provided in $80 \%$ of all lesions, versus observation in $20 \%$. Following removal of lesions reported in studies without dysplasia, low grade dysplasia was reported in $59.9 \%$ of the oral potentially malignant disorders (OPMDs), and high-grade dysplasia in $40.1 \%$ of lesions. In the analysis, overall malignant outcome was $4.99 \%$, and was similar in both the observation and surgical management groups $(p=0.554)$. The overall successful outcome (complete and partial responses) for all treatment was $45.31 \%$, persistence or recurrences were observed in $27.99 \%$ of all OPMDs. In low grade lesions, there was no correlation between the complete or partial responses $(p=0.446)$, and the number of malignant transformation and recurrences/new lesions $(p=0.310)$. Similarly, in high grade lesions, no correlation was observed between the complete or partial responses $(p=0.140)$, and the number of malignant transformation and recurrences/new lesions $(p=0.673)$. Further analyses revealed no differences between the outcomes of surgical treatment and observation in low risk group ( $p=0.358)$ and in high risk group $(p=0.258)$.
\end{abstract}

Conclusion: This analysis shows that OPMDs treated by either surgical removal or observation alone have similar risks of malignant transformation irrespective of the degree of dysplasia, indicating the need for active surveillance of all dysplastic OPMDs.

\section{Introduction}

Varying presence of cellular atypia and tissue dysmaturation restricted to the epithelium are termed oral epithelial dysplasia (OED) [1-3], or oral intraepithelial neoplasia (OIN) [4]. According to the severity of the cellular alterations and the thickness of the epithelium involved $[1,3,5]$, lesions may be classified histologically as squamous hyperplasia, mild dysplasia, moderate dysplasia, severe dysplasia and carcinoma-in-situ (CIS) [6-10]. Across all degrees of dysplasia, an overall annual malignant transformation rate (MTR) is $<1 \%$ per year, and overall risk of malignant transformation is estimated as 3.5\% [1113 ], whereas $39 \%$ of oral dysplasia may regress in follow-up without treatment [10].

Oral dysplastic aberrations may be seen in oral lesions which are defined as oral potentially malignant disorders (OPMDs) [7,11,1417]. Clinical presentations of OPMDs include leukoplakia, speckled leukoplakia, leuko-erythroplakia, speckled erythroplakia, granular erythroplakia $[7,11,18,19]$, erythroplakia $[1,5,15]$, oral lichen planus with dysplasia, and oral submucous fibrosis $[1,5,7,15,20]$.

Scalpel surgery, laser surgery, cryotherapy, photodynamic therapy, topical or systemic medical therapy and observation have been reported among the treatment approaches for dysplastic OPMDs
[21-28]. However, the interpretation of the findings of these studies are challenging due multiple factors including differences in study populations, small sample sizes of studies, nonrandomized study design, and limited follow-up periods. These factors also complicate the evaluation of the outcomes of different treatment modalities. Therefore, the aim of the current systematic analysis is to investigate the outcomes of surgical management of dysplastic OPMDs including leukoplakia, erythroplakia, erythroleukoplakia, oral lichen planus, oral lichenoid lesions, CIS and Stage I OSCC versus observation alone.

\section{Materials and methods}

The Preferred Reporting Items for Systematic review and Metaanalysis (PRISMA) guidelines [29] for selection of papers were followed

${ }^{\star}$ Correspondence to: Pelin Güneri, Department of Oral and Maxillofacial Radiology, School of Dentistry, Ege University, Bornova, İzmir, Turkey, Tel: +902323881081; Fax: +902323880325; E-mail: peleen_2000@yahoo.com

Key words: oral surgery, oral epithelial dysplasia, oral cancer, malignant transformation, leukoplakia

Received: March 05, 2019; Accepted: March 22, 2019; Published: March 25, 2019 
for this study. Final decisions on both inclusion and exclusion of the papers were agreed upon by two authors (PG, JBE) prior to the search process.

The initial literature search was conducted using Web of Science, PubMed and Cochrane databases, including reports published until July 2015. The key words used for searching were ("mouth" (MeSH Terms) OR "mouth" (All Fields) OR "oral" (All Fields)) AND ("precancerous conditions" (MeSH Terms) OR "precancerous conditions" (All Fields) OR "premalignant" (All Fields)) AND lesion (All Fields) AND ("therapy" (Subheading) OR "therapy" (All Fields) OR "treatment" (All Fields) OR "therapeutics" (MeSH Terms) OR "therapeutics" (All Fields)). The initial search identified 866 papers; an additional 26 studies were also collected with manual search (Figure 1).

Following elimination of duplicates, 531 papers were selected for secondary screening. Of these, case reports, reviews, animal studies, non-English papers, studies that reported patients with oral lesions without histologically confirmed diagnosis, cross-sectional studies of the prevalence of oral dysplasia, the investigations missing key variables, and studies which do not report the degree of dysplasia were excluded.

A total of 217 papers were selected for further analysis. The following outcome measures were required for inclusion: the number and gender of the patients, the number of lesions, the histologic grade of the lesions (mild, moderate, severe dysplasia, or carcinoma in-situ (CIS)), the treatment method, the follow-up duration, the rate of clinical or histological responses to the treatment, the rate of recurrences, and the rate of malignant transformation to cancer.
Eligibility of the studies obtained from the search was determined independently by two reviewers (PG, JBE) blinded to each other's selections resulting in 26 papers eligible for initial enrollment. In addition to the observation of the lesions, only the treatment methods that aimed at removal of the lesions such as surgery, laser therapy and cryotherapy were included in the investigation. With this final elimination, a total of 21 papers were selected for systematic analysis (Figure 1).

Data were sub-classified by histologic grade of the lesion (mild, moderate, severe dysplasia, or carcinoma in-situ (CIS)). Cases of mild and moderate epithelial dysplasia were combined and named "low grade epithelial dysplasia" and the cases of severe epithelial dysplasia and CIS were combined and recorded as "high grade epithelial dysplasia" as previously recommended $[30,31]$.

Treatment modalities were grouped for data analysis:1) surgery, 2) laser therapy, 3) cryotherapy, 4) observation, 5) combined surgical therapies. The outcome of each therapy was categorized by clinical outcome as total (complete) response, partial response, malignant transformation and recurrences/ new lesions [32]. When more than one treatment was administered on a group of patients, each treatment modality of that paper was analyzed separately as if it were a single investigation. The treatment outcomes were calculated as the proportion, i.e., the number of patients with above-mentioned treatment responses divided by the number of all patients who received treatment.

Descriptive statistics were used for all variables. Mann-Whitney U test, independent sample $t$ test and Pearson correlation analysis were
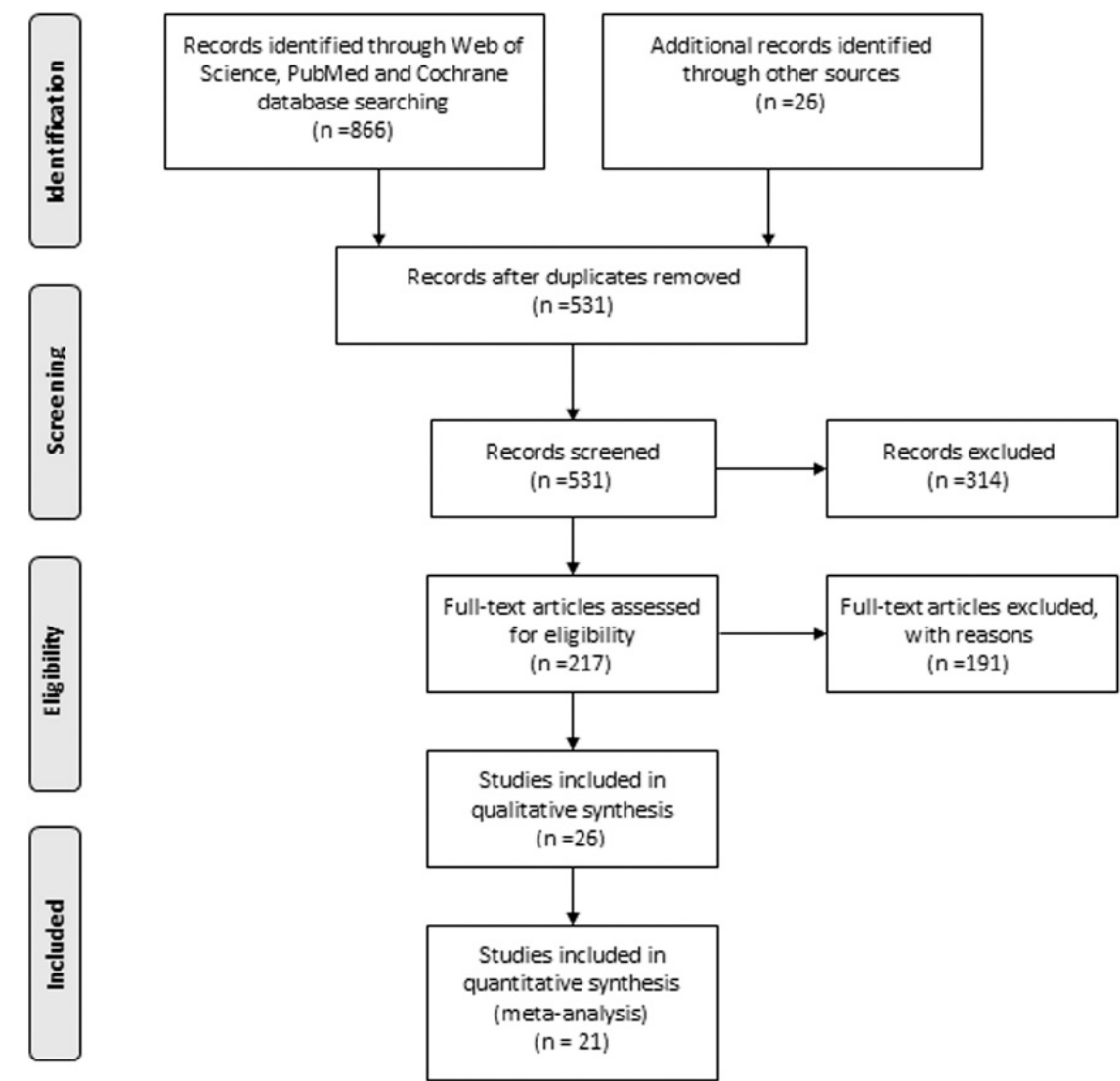

Figure 1. Illustration of anatomic landmarks used for the cephalometric analysis. Sella (S), Nasion (N), Orbitale (Or), Point A: position of deepest concavity on anterior profile of maxilla, Point B: position of deepest concavity on anterior profile of mandible, Pogonion (Pog), Gnathion (Gn), Menton (Me), Anterior Nasal Spine (ANS), Posterior Nasal Spine (PNS), Gonion (Go), Upper Incisor (U1), Lower Incisor (L1), Upper Anterior Facial Height (UAFH): a line connecting Na to ANS, Lower Anterior Facial Height (LAFH): a line connecting ANS to Me. 
used to examine differences and correlations among the groups. The statistical software package SPSS 15.0 (SPSS Inc., Chicago, IL, USA) was used for statistical analyses.

\section{Results}

A total of 21 papers reporting the treatment outcomes of 1,943 lesions observed in 1,599 patients were analyzed in the systematic analysis. Since various treatment methods were utilized in subsets of patients in some studies [5,10,33-36], each modality was considered as a single investigation, resulting in total number of 30 treatment methods in the analysis.

\section{Descriptive analyses}

Of 21 studies, 9 (42.9\%) were prospective [15,32,33,36-41] and 12 (57.1\%) were retrospective. Laser was the most utilized therapy (36.7\%), followed by traditional surgery (26.7\%), clinical observation (20\%), cryotherapy (10\%), and mixed surgical methods (6.7\%), respectively. Of those, six utilized $\mathrm{CO}_{2}$ laser $[15,30,39,42-44]$, three used Nd:YAG laser $[37,38,41]$, whereas two utilized both $[5,45]$. Lasers were applied for lesion ablation except in one study [39], where resection by undercutting of the lesion was performed.

The mean follow-up duration was 57.63 months, ranging from 12 months [32] and 132 months [5]. Smoking and alcohol consumption were reported in $66.7 \%$ of the papers; the number of current/ever smokers ranged between $11.5 \%$ and $86 \%$, whereas alcohol users ranged between $10.5 \%$ and $83 \%[5,10,15,30,33,35,37,39,41,42,44,46-48]$.

Of the included studies, 16 studies (53.3\%) evaluated oral leukoplakia (OL) lesions only [30,32-34,36,38,40,41,43-46], and 14 studies (46.7\%) were completed on other OPMDs (O-OPMD) including combination of leukoplakia, erythroplakia, erythroleukoplakia, CIS, Stage I OSCC, oral lichen planus, oral lichenoid lesions $[5,10,15,35,37,39,42,47,48]$.
In the studies, all investigated parameters were comparable between OL lesions and O-OPMDs (time to recurrence or transformation ( $p$ $=0.479)$, complete response $(p=0.797)$, partial response $(p=0.05)$, malignant transformation $(p=0.617)$, recurrence $(p=0.286))$.

Among O-OPMD lesions, $5.41 \pm 1.26 \%$ and of OL lesions, $4.57 \pm$ 1.53 had malignant transformation. The differences between MTRs of two groups was not statistically significant $(p=0.617)$. Of O-OPMDs, $23.60 \pm 3.89 \%$ recurred during the follow-up, whereas this rate was $22.52 \pm 7.89 \%$ for OL lesions $(p=0.286)$.

\section{Analyses according to dysplastic grade of OPMDs}

When all lesions were considered, $54.48 \%$ presented with low grade dysplasia, $21.98 \%$ had high grade dysplasia, whereas $23.54 \%$ had no dysplasia. Among oral leukoplakia lesions (OLs), 53.37\% were within the low-grade dysplasia and $16.29 \%$ were within the high-grade dysplasia groups. Of OPMDs including combination of leukoplakia, erythroplakia, erythroleukoplakia, CIS, oral lichen planus and oral lichenoid lesions which were referred as other OPMDs (O-OPMDs), $55.75 \%$ presented with low grade and $26.89 \%$ with high grade dysplastic lesions, respectively (Table 1). In this systematic analysis, only lesions with histologic grading of dysplasia were included and benign lesions were excluded from the analyses.

The number of low-grade lesions in OL and O-OPMDs were similar $(p=0.632)$, as with that of the high-grade dysplasia lesions including severe dysplasia and CIS $(p=0.212))$. There was no correlation between the complete or partial responses in low grade lesions $(p=0.446)$, and the number of malignant transformation and recurrences/new lesions $(p=0.310)$. Similarly, no correlation was observed between the complete or partial responses in high grade lesions $(p=0.140)$, and the number of malignant transformation and recurrences/new lesions $(p=$ 0.673) (Table 2).

Table 1. The risk groups, follow-up durations and overall treatment outcomes (observation, conventional surgery, laser surgery and cryosurgery) in oral leukoplakia (OL) and oral premalignant disorders (O-OPMDs)

\begin{tabular}{|c|c|c|c|c|c|c|}
\hline \multirow{7}{*}{ Degree of dysplasia } & \multirow{4}{*}{ Low } & $\mathbf{N}$ & OL & O-OPMD & $P$ value & Total \\
\hline & & $\sqrt{ }$ & 16 & 14 & \multirow{3}{*}{0.632} & 30 \\
\hline & & Mean & 0.53 & 0.56 & & 0.54 \\
\hline & & Std.Dev. & 0.28 & 0.26 & & 0.27 \\
\hline & \multirow{3}{*}{ High } & $\mathrm{N}$ & 11 & 13 & \multirow{3}{*}{0.212} & 24 \\
\hline & & Mean & 0.16 & 0.27 & & 0.22 \\
\hline & & Std.Dev. & 0.12 & 0.19 & & 0.17 \\
\hline \multirow{12}{*}{ Treatment outcomes } & \multirow{3}{*}{ Complete response } & $\mathrm{N}$ & 13 & 8 & \multirow{3}{*}{0.797} & 21 \\
\hline & & Mean & 0.42 & 0.38 & & 0.41 \\
\hline & & Std.Dev. & 0.40 & 0.39 & & 0.39 \\
\hline & \multirow{3}{*}{ Partial response } & $\mathrm{N}$ & 9 & 8 & \multirow{3}{*}{0.05} & 17 \\
\hline & & Mean & 0.00 & 0.09 & & 0.05 \\
\hline & & Std.Dev. & 0.00 & 0.14 & & 0.10 \\
\hline & \multirow{3}{*}{$\begin{array}{l}\text { Malignant transformation } \\
\text { rate }\end{array}$} & $\mathrm{N}$ & 11 & 11 & \multirow{3}{*}{0.617} & 22 \\
\hline & & Mean & 0.05 & 0.05 & & 0.05 \\
\hline & & Std.Dev. & 0.05 & 0.04 & & 0.05 \\
\hline & \multirow{3}{*}{ Recurrence } & $\mathrm{N}$ & 10 & 8 & \multirow{3}{*}{0.286} & 18 \\
\hline & & Mean & 0.23 & 0.24 & & 0.23 \\
\hline & & Std.Dev. & 0.25 & 0.11 & & 0.19 \\
\hline \multirow{3}{*}{\multicolumn{2}{|c|}{ Time to recurrence/malignant transformation }} & $\mathrm{N}$ & 9 & 6 & \multirow{3}{*}{0.479} & 15 \\
\hline & & Mean & 52.01 & 42.9 & & 48.37 \\
\hline & & Std.Dev. & 39.49 & 33.10 & & 36.11 \\
\hline \multirow{3}{*}{\multicolumn{2}{|c|}{ Follow-up duration (months) }} & $\mathrm{N}$ & 16 & 14 & \multirow{3}{*}{0.000} & 30 \\
\hline & & Mean & 37.31 & 78.80 & & 56.67 \\
\hline & & Std.Dev. & 15.13 & 36.21 & & 33.90 \\
\hline
\end{tabular}


Table 2. Comparison of the outcomes of the treatment modalities used for OL and O-OPMDs ( $p$ values)

\begin{tabular}{|l|l|l|l|}
\hline Treatment methods & $\begin{array}{l}\text { Complete } \\
\text { responses }\end{array}$ & $\begin{array}{l}\text { Partial } \\
\text { responses }\end{array}$ & $\begin{array}{l}\text { Malignant } \\
\text { transformation } \\
\text { rate }\end{array}$ \\
\hline Observation- Conventional surgery & 0.851 & 0.573 & 0.624 \\
\hline Observation-Laser & 0.93 & 0.04 & 0.251 \\
\hline Observation-Cryotherapy & 0.313 & 0.182 & 0.127 \\
\hline Conventional surgery-Laser & 0.933 & 0.391 & 0.109 \\
\hline Conventional surgery-Cryotherapy & 0.423 & 0.541 & 0.141 \\
\hline $\begin{array}{l}\text { Observation-Conventional surgery + Laser + } \\
\text { Cryotherapy + Combined surgical therapy }\end{array}$ & 0.726 & 0.241 & 0.554 \\
\hline
\end{tabular}

\section{Treatment modalities}

In this analysis of dysplastic OPMDs, $68.2 \%$ of the lesions received treatment, either surgery, laser therapy or cryosurgery. However, intervention was mostly provided in the prospective studies $(91.25 \%)$ compared to retrospective investigations $(56.67 \%)(p=0.017)$.

Malignant transformation was reported in $4.99 \pm 0.97 \%$, recurrences were observed in $23 \pm 4.59 \%$ of all lesions.

Independent Samples $\mathrm{t}$ test and Pearson correlation analyses revealed that complete and partial response rates were comparable between observation and surgical intervention $(p=0.851$ and $p=$ 0.537 , respectively). Similarly, the MTR in observation groups was not different than that of the surgery groups $(p=0.624)$ (Table 2$)$.

Observation was associated with fewer partial responses when compared with the results of the laser therapy, $(p=0.04)$, however, the complete response and the MTRs were comparable $(p=0.930$ and $p=$ 0.251 , respectively). Observation and cryosurgery also provided similar complete and partial responses, and MTRs $(p=0.313, p=0.182$ and $p$ $=0.127$, respectively) (Table 2 ).

Conventional surgery and laser surgery had similar complete $(p=$ $0.933)$ and partial responses $(p=0.391)$, malignant transformation $(p=$ $0.109)$ and recurrence rates $(p=0.473)$. Similarly, conventional surgery and cryotherapy had comparable complete $(p=0.423)$ and partial responses $(p=0.541)$, malignant transformation and recurrence rates ( $p=0.141$ and $p=0.924$, respectively) (Table 2$)$.

When the results of all surgical management methods (conventional surgery, laser surgery, cryosurgery and combined surgery) were grouped and the outcomes were compared with those of observation alone, similar complete $(p=0.726)$ and partial responses $(p=0.241)$, malignant transformation rates $(p=0.554)$ and recurrences $(p=0.960)$ were observed (Table 2).

\section{Discussion and conclusion}

In the present paper, the recurrence rates were highly variable for OL, as reported previously with recurrence rates ranging from 7.7 to $38.1 \%$ [42,43,49-52]. In the current analysis, recurrences were observed in $23 \%$ of all treated lesions, within the range reported in the literature.

A subset of OPMDs may progress to OSCC despite active treatment and active follow-up [3,11,35,53-56]. Unfortunately, it is not possible to predict if and when a potential precancerous lesion will transform to cancer $[11,34,57-60]$, since there are no reliable clinical, histological parameters or molecular tests available for clinical use that predict the transformation potential of OPMDs $[10,58,60]$.

The MTR observed in this analysis (4.99\%) was within this range. The length of follow-up has been identified as one of the variables in the
MTRs of OPMDs among the studies [53,61]. Malignant transformation has been reported to be between $1.5-10$ years $[6,20,53]$ and beyond 20 years [58].

The degree of dysplasia and the anatomical site were the two influential factors in a proposed follow-up schema [16]. Despite these studies showing progression to cancer, it has been suggested that patients who remain disease free for 3 years after treatment may not require follow-up on a scheduled basis [62]. Some authors report that severe epithelial dysplasia increases the risk of malignant transformation [2,9,30,33,50,53-56,63-65]. Thus, follow-up regimens of 6 monthly for lichen planus, leukoplakia/mixed and erythroplakia lesions without dysplasia, 3 monthly for mild/moderate dysplasia, and monthly for severe dysplasia/CIS were suggested $[59,66,67]$. However, it is important to note that others have not seen an association between the grade of dysplasia and transformation rates $[3,10,11,35,43,44]$. Even histologically innocuous lesions have progressed to OSCC $[9,41,62]$ and OSCC may arise de novo or at different locations than the site of the treated lesions or in the absence of clinically detected mucosal change $[30,42,44,61]$.

There is no general consensus on the treatment of OPMDs [68], and surgery has been reported to have limited or no effect in a number of studies [10,12]. This may be the case as local procedures may not adequately address the extent of molecular change in the epithelium, adjacent connective tissue, nor the oral microenvironment, and potential multiple independent foci of abnormal cells within the epithelium may give rise to development of multiple primary cancers and recurrences [42]. Conversely, it is unclear if dysplasia, when surgically treated, is given consistent management typically afforded in cases of biopsy proven malignancy (wide margins, frozen sections beyond resection), because these approaches are less likely in less severe grades of dysplasia. Even though in our analysis, the papers that preferred surgical management methods utilized a safety margin of 3-5 $\mathrm{mm}$, the variability in surgical management including narrow margins or greater attention to preservation of nearby structures to reduce potential morbidity of treatment, given the limited risk of progression of OPMDs to cancer, may confound the potential efficacy of surgical intervention.

In this paper, the included studies' clinical treatment outcome has been associated with continuing smoking $[10,15,30,39,42,48]$ and alcohol consumption $[5,10,30,42]$, although alcohol consumption $[15,33,39,46]$ and tobacco relation were not clear in some others $[33,35,46,47]$.

Our analysis revealed that lesions with low grade dysplasia behaved similarly to high risk lesions with respect to malignant transformation irrespective of surgical treatment or observation. Similarly, a recent study reported that the treatment outcome is associated with both the inherent nature of the OPMD and the treatment method [69]. The failure of the treatment of a lesion was thought to indicate the aggressiveness and increased malignancy potential, but this assumption was not supported in a retrospective investigation which revealed malignancy did not necessarily develop in treatment resistant lesions [69]. Even though some clinicians prefer to excise severely dysplastic lesions due to potential higher malignancy risk and to observe lesions with mild and moderate dysplasia which possibly have lower risk [70], our systematic analysis showed that patients who received surgical treatment have a similar risk for malignant transformation with those who remained under surveillance without surgical intervention. Among previous studies, only one favored surgical intervention rather than observation 
[5], and active treatment and observation groups provided comparable risks for malignant changes $[10,33,35]$. This has been attributed to the potential triggering effect of surgery on lesion microenvironment and immune and inflammatory mediators [35]. The presence of molecular alterations harbored in oral mucosa are not detectable by clinical or histological examination $[16,32,45,61,62,71,72]$ which complicates the potential of local surgical therapy to cure and prevent new lesions within all at-risk tissue exposed to potential carcinogens $[44,71,73]$.

Several caveats deserve mention that may limit generalizability of our results, including selection and publication bias inherent in metaanalyses. New premalignant or malignant lesions at a different site may not indicate the lack of efficacy of a particular treatment, rather, it may be due to pre-malignant or malignant clones arising or migrating outside of the area of treatment [61]. Another confounder may be interpathologist variability in interpretation of identification and grading of dysplasia. Similarly, reversal of the lesions without intervention has been seen and may be associated with the termination of potentially carcinogenic habits, or treatment of superimposed confounding factors such as candidiasis and other local irritants or may represent remission due to immune processes $[10,35]$.

The decision to manage surgically is usually based upon the presence and severity of dysplasia which are assessed following biopsy, the extent of the lesion, the presence of single or multiple lesions, patient anxiety and compliance for follow-up. Therefore, due to the presence of provider bias and study heterogeneity $[5,12,46,74]$ current data is limited in guiding current practice and meticulous follow-up of all mucosal lesions is mandatory [32]. The search for effective approaches for preventive or curative treatment of such lesions include systemic and topical chemoprevention to arrest or reverse the process of malignant transformation is sought but remains to be defined $[16,61]$. The degree of dysplasia as reported on biopsy may consequently not reflect the natural history of potentially malignant disorders and inclusion of cellular/molecular markers or chromosomal changes continues to be sought to predict the cellular behavior of OPMDs [11,75].

Within the limitations of this systematic analysis, no significant impact upon outcomes of surgical management of dysplastic oral lesions compared to active surveillance was seen. More definitive guidance for management of OPMDs with dysplasia requires collaborative multicenter, prospective, long-term and controlled studies employing well defined clinical and histological criteria.

\section{References}

1. Bouquot JE, Speight PM, Farthing PM (2006) Epithelial dysplasia of the oral mucosaDiagnostic problems and prognostic features. Curr Diagn Pathol 12: 11-21.

2. Mehanna HM, Rattay T, Smith J, McConkey CC (2009) Treatment and follow-up of oral dysplasia - a systematic review and meta-analysis. Head Neck 31: 1600-1609. [Crossref]

3. Dost F, Lê Cao K, Ford PJ, Ades C, Farah CS (2014) Malignant transformation of oral epithelial dysplasia: a real-world evaluation of histopathologic grading. Oral Surg Oral Med Oral Pathol Oral Radiol 117: 343-352. [Crossref]

4. Mallery SR, Tong M, Shumway BS, Curran AE, Larsen PE, et al. (2014) Topical application of a mucoadhesive freeze-dried black raspberry gel induces clinical and histologic regression and reduces loss of heterozygosity events in premalignant oral intraepithelial lesions: results from a multicentered, placebo-controlled clinical trial. Clin Cancer Res 20: 1910-1924. [Crossref]

5. Arnaoutakis D, Bishop J, Westra W, Califano JA (2013) Recurrence patterns and management of oral cavity premalignant lesions. Oral Oncol 49: 814-817. [Crossref]

6. Lumerman H, Freedman P, Kerpel S (1995) Oral epithelial dysplasia and the development of invasive squamous cell carcinoma. Oral Surg Oral Med Oral Pathol Oral Radiol Endod 79: 321-329. [Crossref]
7. van der Waal I, Axéll T (2002) Oral leukoplakia: a proposal for uniform reporting. Oral Oncol 38: 521-526. [Crossref]

8. Poh CF, Ng S, Berean KW, Williams PM, Rosin MP, et al. (2008) Biopsy and histopathologic diagnosis of oral premalignant and malignant lesions. J Can Dent Assoc 74: 283-288. [Crossref]

9. Warnakulasuriya S, Reibel J, Bouquot J, Dabelsteen E (2008) Oral epithelial dysplasia classification systems: predictive value, utility, weaknesses and scope for improvement J Oral Pathol Med 37: 1271-33. [Crossref]

10. Arduino PG, Surace A, Carbone M, Elia A, Massolini G, et al. (2009) Outcome of oral dysplasia: a retrospective hospital-based study of 207 patients with a long follow-up. $J$ Oral Pathol Med 38: 540-544. [Crossref]

11. Brennan M, Migliorati CA, Lockhart PB, Wray D, Al-Hashimi I, et al. (2007) Management of oral epithelial dysplasia: a review. Oral Surg Oral Med Oral Pathol Oral Radiol Endod 103: S19.e1-S12. [Crossref]

12. Lodi G, Porter S (2008) Management of potentially malignant disorders: evidence and critique. J Oral Pathol Med 37: 63-69. [Crossref]

13. Warnakulasuriya S, Ariyawardana A (2016) Malignant transformation of oral leukoplakia: a systematic review of observational studies. J Oral Pathol Med 45: 155166. [Crossref]

14. Lee JJ, Hung HC, Cheng SJ, Chen YJ, Chiang CP, et al. (2006) Carcinoma and dysplasia in oral leukoplakias in Taiwan: prevalence and risk factors. Oral Surg Oral Med Oral Pathol Oral Radiol Endod 101: 472-480. [Crossref]

15. Diajil A, Robinson CM, Sloan P, Thomson PJ (2013) Clinical outcome following oral potentially malignant disorder treatment: a 100 patient cohort study. Int J Dent 2013: 809248.

16. Foy JP, Bertolus C, William WN Jr, Saintigny P (2013) Oral premalignancy: the roles of early detection and chemoprevention. Otolaryngol Clin North Am 46: 579-597. [Crossref]

17. Güneri P, Epstein JB2 (2014) Late stage diagnosis of oral cancer: components and possible solutions. Oral Oncol 50: 1131-1136. [Crossref]

18. Reichart PA, Philipsen HP (2005) Oral erythroplakia--a review. Oral Oncol 41: 551561. [Crossref]

19. http://www.globaloralcancerforum.org/presentations.php

20. Warnakulasuriya S, Kovacevic T, Madden P, Coupland VH, Sperandio M, et al. (2011) Factors predicting malignant transformation in oral potentially malignant disorders among patients accrued over a 10-year period in South East England. J Oral Pathol Med 40: 677-683. [Crossref]

21. Van der Meij EH, Schepman KP, Van der Waal I (2003) The possible premalignant character of oral lichen planus and oral lichenoid lesions: a prospective study. Oral Surg Oral Med Oral Pathol Oral Radiol Endod 96: 164-171. [Crossref]

22. Lodi G, Scully C, Carrozzo M, Griffiths M, Sugerman PB, et al. (2005) Curren controversies in oral lichen planus: report of an international consensus meeting. Part 2. Clinical management and malignant transformation. Oral Surg Oral Med Oral Pathol Oral Radiol Endod 100: 164-178. [Crossref]

23. Al-Hashimi I, Schifter M, Lockhart PB, Wray D, Brennan M, et al. (2007) Oral lichen planus and oral lichenoid lesions: diagnostic and therapeutic considerations. Oral Surg Oral Med Oral Pathol Oral Radiol Endod 103: S25.e1-S12. [Crossref]

24. Van der Meij EH, Mast H, Van der Waal I (2007) The possible premalignant character of oral lichen planus and oral lichenoid lesions: a prospective five-year follow-up study of 192 patients. Oral Oncol 43: 742-748. [Crossref]

25. Farhi D, Dupin N (2010) Pathophysiology, etiologic factors, and clinical managemen of oral lichen planus, part I: Facts and controversies. Clin Dermatol 28: 100-108. [Crossref]

26. Malik U, Gupta S, Malik SD, Vashishth S, Zaheeruddin, et al. (2012) Treatment of symptomatic oral lichen planus (OLP) with $0.1 \%$ tacrolimus powder in Oraguard-B - A pilot prospective study. Saudi Dent J 24: 143-148. [Crossref]

27. Van der Waal I (2014) Oral potentially malignant disorders: is malignant transformation predictable and preventable? Med Oral Patol Oral Cir Bucal 19: e386-e390. [Crossref]

28. Garcia-Pola MJ, Llorente-Pendás S, González-Garcia M, García-Martín JM (2016) The development of proliferative verrucous leukoplakia in oral lichen planus. A preliminary study. Med Oral Patol Oral Cir Bucal 21: e328-e334. [Crossref]

29. Liberati A, Altman DG, Tetzlaff J, Mulrow C, Gøtzsche PC, et al. (2009) The PRISMA statement for reporting systematic reviews and meta-analyses of studies that evaluate health care interventions: explanation and elaboration. J Clin Epidemiol 62: e1-e34. 
30. Chandu A, Smith AC (2005) The use of $\mathrm{CO} 2$ laser in the treatment of oral white patches: outcomes and factors affecting recurrence. Int J Oral Maxillofac Surg 34: 396400. [Crossref]

31. Accurso BT, Warner BM, Knobloch TJ, Weghorst CM, Shumway BS, et al. (2011) Allelic imbalance in oral lichen planus and assessment of its classification as a premalignant condition. Oral Surg Oral Med Oral Pathol Oral Radiol Endod 112: 359366. [Crossref]

32. Pandey M, Thomas G, Somanathan T, Sankaranarayanan R, Abraham EK, et al. (2001) Evaluation of surgical excision of non-homogeneous oral leukoplakia in a screening intervention trial, Kerala, India. Oral Oncol 37: 103-109. [Crossref]

33. Schepman KP, Van der Meij EH, Smeele LE, Van der Waal I (1998) Malignant transformation of oral leukoplakia: a follow-up study of a hospital-based population of 166 patients with oral leukoplakia from The Netherlands. Oral Oncol 34: 270-275. [Crossref]

34. Saito T, Sugiura C, Hirai A, Notani K, Totsuka Y, et al. (2001) Development of squamous cell carcinoma from pre-existent oral leukoplakia: with respect to treatment modality. Int J Oral Maxillofac Surg 30: 49-53. [Crossref]

35. Holmstrup P, Vedtofte P, Reibel J, Stoltze K (2006) Long-term treatment outcome of oral premalignant lesions. Oral Oncol 42: 461-474. [Crossref]

36. Kawczyk-Krupka A, Waskowska J, Raczkowska-Siostrzonek A, Kosciarz-Grzesiok A, Kwiatek S, et al. (2012) Comparison of cryotherapy and photodynamic therapy in treatment of oral leukoplakia. Photodiagnosis Photodyn Ther 9: 148-155. [Crossref]

37. Tewari M, Rai P, Singh GB, Kumar M, Shukla HS (2007) Long-term follow-up results of Nd: YAG laser treatment of premalignant and malignant (Stage I) squamous cell carcinoma of the oral cavity. J Surg Oncol 95: 281-285. [Crossref]

38. Vivek V, Jayasree RS, Balan A, Sreelatha KT, Gupta AK (2008) Three-year follow-up of oral leukoplakia after neodymium:yttrium aluminum garnet (Nd:YAG) laser surgery. Lasers Med Sci 23: 375-379. [Crossref]

39. Hamadah O, Thomson PJ (2009) Factors affecting carbon dioxide laser treatment for oral precancer: a patient cohort study. Lasers Surg Med 41: 17-25. [Crossref]

40. Yu CH, Chen HM, Chang CC, Hung HY, Hsiao CK, et al. (2009) Cotton-swab cryotherapy for oral leukoplakia. Head Neck 31: 983-988. [Crossref]

41. Das S, Mohammad S, Singh V, Gupta S (2015) Neodymium:Yttrium aluminum garnet laser in the management of oral leukoplakia: A case series. Contemp Clin Dent 6: S32-S35. [Crossref]

42. Thomson PJ, Wylie J (2002) Interventional laser surgery: an effective surgical and diagnostic tool in oral precancer management. Int J Oral Maxillofac Surg 31: 145-153. [Crossref]

43. van der Hem PS, Nauta JM, van der Wal JE, Roodenburg JL (2005) The results of CO2 laser surgery in patients with oral leukoplakia: a 25 year follow up. Oral Oncol 41: 31-37. [Crossref]

44. Mogedas-Vegara A, Hueto-Madrid JA2, Chimenos-Küstner E3, Bescós-Atín C2 (2015) The treatment of oral leukoplakia with the $\mathrm{CO} 2$ laser: A retrospective study of 65 patients. J Craniomaxillofac Surg 43: 677-681. [Crossref]

45. Del Corso G, Gissi DB, Tarsitano A, Costabile E, Marchetti C, et al. (2015) Laser evaporation versus laser excision of oral leukoplakia: A retrospective study with longterm follow-up. J Craniomaxillofac Surg 43: 763-768. [Crossref]

46. Kuribayashi Y, Tsushima F, Sato M, Morita K, Omura K (2012) Recurrence patterns of oral leukoplakia after curative surgical resection: important factors that predict the risk of recurrence and malignancy. J Oral Pathol Med 41: 682-688. [Crossref]

47. Holmstrup P, Vedtofte P, Reibel J, Stoltze K (2007) Oral premalignant lesions: is a biopsy reliable? J Oral Pathol Med 36: 262-266. [Crossref]

48. Casparis S, Borm JM, Tektas S, Kamarachev J, Locher MC et al (2015) Oral lichen planus (OLP), oral lichenoid lesions (OLL), oral dysplasia, and oral cancer: retrospective analysis of clinicopathological data from 2002-2011. Oral Maxillofac Surg 19: 149-156. [Crossref]

49. Vedtofte P, Holmstrup P, Hjorting-Hansen E, Pindborg JJ (1987) Surgical treatment of premalignant lesions of the oral mucosa. Int J Oral Maxillofac Surg 16: 656-664. [Crossref]

50. Chiesa F, Tradati N, Sala L, Costa L, Podrecca S, et al. (1990) Follow up of oral leukoplakia after carbon dioxide laser surgery. Arch Otolaryngol Head Neck Surg 116: 177-180. [Crossref]

51. Schoelch ML, Sekandari N, Regezi JA, Silverman S Jr (1999) Laser management of oral leukoplakias: a follow-up study of 70 patients. Laryngoscope 109: 949-953. [Crossref]

52. Ishii J, Fujita K, Komori T (2003) Laser surgery as a treatment for oral leukoplakia. Oral Oncol 39: 759-769. [Crossref]
53. Silverman S Jr, Gorsky M, Lozada F (1984) Oral leukoplakia and malignant transformation. A follow-up study of 257 patients. Cancer 53: 563-568. [Crossref]

54. Gupta PC, Bhonsle RB, Murti PR, Daftary DK, Mehta FS, et al. (1989) An epidemiologic assessment of cancer risk in oral precancerous lesions in India with special reference to nodular leukoplakia. Cancer 63: 2247-2252. [Crossref]

55. Neville BW, Damm DD, Allen CM, Bouquot JE (2002) Epithelial pathology. ( $2^{\text {nd }}$ edn), Oral and maxillofacial pathology. Philadelphia: W.B. Saunders Company, pp: 337-346.

56. Reibel J (2003) Prognosis of oral pre-malignant lesions: significance of clinical, histopathological, and molecular biological characteristics. Crit Rev Oral Biol Med 14 47-62. [Crossref]

57. Warnakulasuriya S (2000) Lack of molecular markers to predict malignant potential of oral precancer. J Pathol 190: 407-409. [Crossref]

58. Carinci F, Lo Muzio L, Piattelli A, Rubini C, Palmieri A, et al. (2005) Genetic portrait of mild and severe lingual dysplasia. Oral Oncol 41: 365-374. [Crossref]

59. Nankivell P, Williams H, Matthews P, Suortamo S, Snead D, et al. (2013) The binary oral dysplasia grading system: validity testing and suggested improvement. Oral Surg Oral Med Oral Pathol Oral Radiol 115: 87-84. [Crossref]

60. Edwards PC (2014) The natural history of oral epithelial dysplasia: perspective on Dost et al. Oral Surg Oral Med Oral Pathol Oral Radiol 117: 263-266. [Crossref]

61. Ha PK, Califano JA (2003) The molecular biology of mucosal field cancerization of the head and neck. Crit Rev Oral Biol Med 14: 363-369. [Crossref]

62. van der Waal I, Schepman KP, van der Meij EH, Smeele LE (1997) Oral leukoplakia: a clinicopathological review. Oral Oncol 33: 291-301. [Crossref]

63. Lee JJ, Hong WK, Hittelman WN, Mao L, Lotan R, et al. (2000) Predicting cance development in oral leukoplakia: ten years of translational research. Clin Cancer Res 6: 1702-1710. [Crossref]

64. Van der Waal I (2010) Potentially malignant disorders of the oral and oropharyngeal mucosa; present concepts of management. Oral Oncol 46: 423-425. [Crossref]

65. Liu W, Shi LJ, Wu L, Feng JQ, Yang X, et al. (2012) Oral cancer development in patients with leukoplakia--clinicopathological factors affecting outcome. PLoS One 7: e34773. [Crossref]

66. Marley JJ, Linden GJ, Cowan CG, Lamey PJ, Johnson NW, et al. (1998) A comparison of the management of potentially malignant oral mucosal lesions by oral medicine practitioners and oral \& maxillofacial surgeons in the UK. J Oral Pathol Med 27: 489495. [Crossref]

67. Epstein JB, Gorsky M, Fischer D, Gupta A, Epstein M, et al. (2007) A survey of the current approaches to diagnosis and management of oral premalignant lesions. $J \mathrm{Am}$ Dent Assoc 138: 1555-1562. [Crossref]

68. Kumar A, Cascarini L, McCaul JA, Kerawala CJ, Coombes D, et al. (2013) How should we manage oral leukoplakia? Br J Oral Maxillofac Surg 51: 377-383. [Crossref]

69. Thomson PJ, Goodson ML1,2, Smith DR2 (2017) Treatment resistance in potentially malignant disorders-'Nature' or 'Nurture'..? J Oral Pathol Med 46: 902-910. [Crossref]

70. Thomson PJ, McCaul JA, Ridout F, Hutchison IL (2015) To treat...or not to treat? Clinicians' views on the management of oral potentially malignant disorders. Br J Oral Maxillofac Surg 53:1027-1031.

71. Epstein JB, Zhang L, Rosin M (2002) Advances in the diagnosis of oral premalignant and malignant lesions. J Can Dent Assoc 68: 617-621. [Crossref]

72. Holmstrup $\mathrm{P}$ (2009) Can we prevent malignancy by treating premalignant lesions? Oral Oncol 45: 549-550. [Crossref]

73. Angadi PV, Savitha JK, Rao SS, Sivaranjini Y (2012) Oral field cancerization: current evidence and future perspectives. Oral Maxillofac Surg 16: 171-180. [Crossref]

74. Lodi G, Franchini R, Warnakulasuriya S, Varoni EM, Sardella A, et al. (2016) Interventions for treating oral leukoplakia to prevent oral cancer. Cochrane Database Syst Rev 7: CD001829. [Crossref]

75. Dionne KR, Warnakulasuriya S, Zain RB, Cheong SC (2015) Potentially malignant disorders of the oral cavity: current practice and future directions in the clinic and laboratory. Int J Cancer 136: 503-515. [Crossref]

Copyright: (C2019 Güneri P. This is an open-access article distributed under the terms of the Creative Commons Attribution License, which permits unrestricted use, distribution, and reproduction in any medium, provided the original author and source are credited. 